\title{
A RESOLUÇÃO 287 DO CNJ E OS DIREITOS DA PESSOA INDÍGENA NO SISTEMA PRISIONAL BRASILEIRO
}

\author{
Waldilena Assunção ${ }^{1}$ \\ Valdir Florisbal Jung**
}

\section{Resumo}

O presente trabalho busca refletir sobre o poder do Estado nos procedimentos e o tratamento dado as pessoas indígenas acusadas, rés, condenadas ou privadas de liberdade à luz do ordenamento não tradicional e a questão da efetividade dos direitos da pessoa indígena no sistema prisional brasileiro. Assim, buscou-se fazer revisões de bibliografias e análises da Resolução 287 do Conselho Nacional de Justiça-CNJ, de 25 junho de 2019, que veio preencher a lacuna existente no que diz respeito à resposta do Poder Judiciário para a questão do indígena privado de liberdade em todo o país.

Palavras-Chave: Direito indígena; Réu Indígena; Imputabilidade; Privação de Liberdade.

\section{CNJ RESOLUTION 287 AND THE RIGHTS OF THE INDIGENOUS PERSON ON THE BRAZILIAN PRISON SYSTEM}

\begin{abstract}
This paper seeks to reflect on the power of the State in the procedures and treatment given to indigenous persons accused, defendant, convicted or deprived of liberty in the light of non-traditional ordering and the issue of the effectiveness of indigenous people's rights in the Brazilian prison system. Thus, we sought to review the bibliographies and analyzes of Resolution 287 of the National Council of Justice (CNJ) of June 25, 2019, filled the gap regarding the response of the Judiciary to the indigenous question deprived of liberty throughout the country.
\end{abstract}

Keywords: Indigenous law; Indigenous Defendant; Imputability; Deprivation of Liberty.

\section{Introdução}

\footnotetext{
${ }^{1}$ Mestranda do Programa de Pós-Graduação em Antropologia - PPGA/UFPA. Especialista em Gestão Pública pela Universidade da Amazônia - UNAMA. Bacharel em Direito e Serviço Social. E-mail: waldilenaas@yahoo.com.br.

** Advogado. Mestrando no Programa de Mestrado em Direitos Humanos da UniRitter (RS). Especialista em Direito Penal e Processo Penal pela Ulbra. Especialista em Docência do Ensino Superior pelo Centro Universitário Leonardo da Vinci - IERGS. Bacharel em Direito pela Ulbra. Professor convidado da Pós-Graduação Latu Sensu da UniRitter. E-mail: valdirjung.adv@gmail.com.
} 
No Brasil, o tratamento jurídico-penal dispensado aos indígenas, desde a fase de inquérito policial, é tema pouco recorrente e, por vezes, desconhecido dos operadores do direito, que não têm o entendimento antropológico da cultura indígena e aplicam sanções com base em normativas que não respeitam o modo de viver tradicional e a autodeterminação dos sujeitos indígenas. Segundo Castilho (2019, p. 127), o tema indígena é pouco aprofundado nos manuais de direito penal, processo penal e execução penal e acabam esquecidos ou até ignorados. Neste interim, é importante ressaltar que em nossas jurisprudências o tema ainda é tratado como o debate antigo sobre a imputabilidade, esquecendo o paradigma da diversidade étnica e cultural previsto em nossa Constituição Federal de 1988, em seu art. 231, na Convenção 169 da Organização Internacional do Trabalho - OIT e no próprio Estatuto do Índio quanto a aplicabilidade da pena pelo Estado.

Segundo o Instituto Brasileiro de Geografia e Estatística - IBGE (2010), existem 896 mil pessoas autodeclaradas indígenas no Brasil, distribuídas em 305 etnias e com 274 idiomas mapeados. Sendo que desses, 36,2\% localizados em área urbana e 63,8\% na área rural. Os indígenas correspondem a aproximadamente $0,47 \%$ da população total do país. A questão jurídico-penal na política criminal precisa ser (re) vista, uma vez que, segundo dados de 2016 do Departamento Penitenciário Nacional (DEPEN) ${ }^{2}$, há 726.712 pessoas presas no Brasil, desses $0,08 \%$ dos presos brasileiros eram indígenas. Contudo, esse percentual é bem maior, tendo em vista que muitos não são registrados como indígenas quando presos, e esse desrespeito à autodeterminação inviabiliza uma defesa adequada. Sendo assim, é preciso chamar a atenção sobre o aumento dos índices prisionais quando se trata de indígenas.

Dada a invisibilidade étnica nas prisões, os índices de presos indígenas são bem maiores, pois existe um desrespeito à autodeterminação no sistema jurídico e carcerário brasileiro, que se inicia na fase de inquérito e segue até a fase executória da pena, dentro de um sistema de informação que ainda não está preparado para lidar com as diferenças.

O presente artigo se propõe a discutir o poder do Estado sobre o indígena em conflito com a lei à luz do ordenamento não tradicional e a questão das garantias processuais em respeito à legislação especial. Diante do "Jus Puniendi", no que concerne o poder de punir do Estado, as lutas pelas garantias processuais ao indígena considerado imputável, diante da omissão deixada pelo Código Penal, desde 1940, e o esquecimento da legislação especial, é importante trazer reflexões sobre tais questões para conseguir, assim, subsidiar instrumentos que possam garantir os direitos aos indígenas envolvidos em processos criminais.

Assim, procurar-se-á aqui desmistificar a ideia da inimputabilidade do indígena, presente em uma parcela da população, considerando que ele responde pelos crimes que lhe são imputados no Código Penal Brasileiro. É preciso refletir sobre esse poder de punir do Estado que, por vezes, toma-lhe a liberdade e o coloca em instituições totais

2 DEPARTAMENTO PENITENCIÁRIO NACIONAL é um órgão cuja atuação se dá na área de segurança pública, subordinado ao Ministério da Segurança Pública. Órgão executivo, ele acompanha e controla a aplicação da Lei de Execução Penal e das diretrizes da Política Penitenciária Nacional, emanadas, principalmente, pelo Conselho Nacional de Política Criminal e Penitenciária - CNPCP. Além disso, o Departamento é o gestor do Fundo Penitenciário Nacional - FUNPEN, criado pela Lei Complementar $n^{\circ} 79$, de 07 de janeiro de 1994, e regulamentado pelo Decreto $n^{\circ} 1.093$, de 23 de março de 1994. 
como os presídios, pela aplicabilidade da Lei de Execução Penal. O Estado comete etnocídio ao impor regras e o convívio com uma nova maneira de ser, estar e agir, fora de seu contexto cultural, um convívio apartado e desconsidera as legislações especiais elencadas no Estatuto do Índio e a Convenção 169 da Organização Internacional do Trabalho (OIT).

Como exemplo, cita-se os indígenas do Estado do Pará, que compõe a Amazônia Legal, objeto de estudo em andamento ${ }^{3}$. Trata-se de um estado de grande extensão territorial, de biodiversidade, de riquezas minerais e naturais e potencial hídrico. Contudo, reflete também uma diversidade de questões sociais, principalmente ligada às tensões sociais que envolvem as comunidades tradicionais e o poder estatal nas concessões para construção de grandes obras desenvolvimentistas e as consequências dos impactos socioambientais. ${ }^{4}$

Há de se observar ainda as questões fundiárias e de lutas pelos direitos dos grupos historicamente oprimidos, que vêm cada vez mais sendo criminalizados por lutar pelos seus direitos e, no caso dos indígenas, sofrendo sanções e sendo colocados na condição de réu de uma legislação diferente do seu modo tradicional de ser. Neste contexto, é pertinente compreender adiante como a legislação penal brasileira vem sendo aplicada ao indígena que passa pelo processo criminal e como a Resolução $\mathrm{n}^{\circ} 287$ $(\mathrm{CNJ}, 2019)^{5}$ pode contribuir para garantir os direitos da pessoa indígena no sistema prisional brasileiro.

\section{Na ótica dos sujeitos debatendo a imputabilidade do indígena na realidade brasileira}

No Código Penal Brasileiro (BRASIL, 1940), a questão indígena é completamente omissa. Tal situação não aconteceu por esquecimento, ela é fruto de uma opção da Comissão de Elaboração do Código Penal àquela época, que não tinha representatividade indigenista. Assim, não se fez expressa referência ao indígena como sujeito, e sim como objeto a ser tutelado, tratando-os enquanto cláusula desenvolvimento mental incompleto como inimputável. A opção por não fazer expressa referência ao indígena foi uma opção preconceituosa para que a comunidade internacional não imaginasse que o Brasil era um país infestado de "gentios".

É fato que, em grande parte das questões jurídicas, dos artigos e teses publicadas no país, o não indígena (homem branco) figura como o intelectual universal, sem desmerecer seus conhecimentos processuais penais e suas práticas operativas no

\footnotetext{
3 A temática aqui abordada é fruto da produção acadêmica para a dissertação de Mestrado que foi qualificada em 16 de maio de 2019, por Waldilena Assunção, com o título provisório: “A Criminalização do Indígena e os Direitos Étnicos nas Prisões: Dados Preliminares da Situação Prisional de Indígenas no Estado do Pará", do Curso de Pós-Graduação em Antropologia da Universidade Federal do ParáPPGA/IFCH/UFPA.

${ }^{4}$ Como exemplo tem-se a implantação da Usina Hidrelétrica de Belo Monte, construída no Rio Xingu, no município de Altamira, no Estado do Pará, que geriu grandes discussões não apenas no Brasil, mas no mundo, dada a repercussão acerca do grande impacto ambiental que causou e vem causando às comunidades locais.

${ }^{5}$ BRASIL. Conselho Nacional de Justiça, 2019. Resolução 287, de 25 de junho de 2019. Disponível em: $<$ http://www.cnj.jus.br/atos-normativos?documento=2959>. Acesso em 17 ago.2019.
} 
direito, quando o tema é direito indigenista. Em consonância com a Convenção 169 da OIT, deve-se buscar encontrar intelectuais específicos indígenas, que em suas experiências práticas coadunem o cotidiano jurídico do saber tradicional com o saber cientifico, para que se possa refletir sobre a imputabilidade dos seus parentes (expressão habitualmente utilizada pelos indígenas no Brasil) e a realidade das prisões.

Ressalta-se que os intelectuais indígenas que figuram no cenário político brasileiro são sujeitos que, em conjunto de seus parentes que adentram o universo acadêmico, têm hoje o instrumento da linguagem científica para lutar pelos seus direitos, aliando aos seus saberes tradicionais à sua consciência política de pertença, que, em essência, vem sendo insumo para o empoderamento e as lutas pelos povos tradicionais, principalmente quando envolve violações de direitos e o desrespeito à Convenção 169 do OIT.

Neste interim, o intelectual ocupa um papel importante nestas discussões:

Pode-se supor que o intelectual "universal", tal como funcionou no século XIX e no começo do século XX, derivou de fato de uma figura histórica bem particular: o homem da justiça, o homem da lei, aquele que opõe a universidade da justiça e a equidade de uma lei ideal ao poder, ao despotismo, ao abuso, à arrogância da riqueza. As grandes lutas políticas no século XVIII se fizeram em torno da lei, do direito, da constituição, daquilo que é justo por razão e por natureza, daquilo que pode e deve valer universalmente. $O$ que hoje se chama "o intelectual" (quero dizer o intelectual no sentido político, e não sociológico ou profissional da palavra, ou seja, aquele que faz uso de seu saber, de sua competência, de sua relação com a verdade nas lutas políticas) nasceu, creio do jurista; ou em todo caso, do homem que reivindicava a universalidade da lei justa, eventualmente contra os profissionais do direito (na França, Voltaire é o protótipo destes intelectuais). O intelectual "universal" deriva do jurista-notável e tem sua expressão mais completa no escritor, portador de significações e de valores em que todos podem se reconhecer. $\mathrm{O}$ intelectual "específico" deriva de uma figura muito diversa do "jurista-notável": o "cientista-perito". (FOUCAULT, 2005, p.7)

Neste cenário, é importante fazer referência ao indígena Wilson Matos da Silva, advogado no Mato Grosso do Sul que vem lutando pelos direitos indígenas e que escreve matérias que tratam da situação indígena no Brasil, entre as discussões sobre o tema indígena e as prisões. Temos ainda o advogado Luiz Henrique Eloy ${ }^{6}$, do povo Terena, que também é outro estudioso em matéria indígena. Assim, esses "intelectuais específicos" ressaltados por Foucault, pode-se assim dizer, têm representatividade pelas suas lutas políticas. Atuam no Mato Grosso do Sul, estado brasileiro com o maior índice carcerário indígena ${ }^{7}$, e vêm tentando esclarecer a questão da imputabilidade dos

\footnotetext{
${ }^{6}$ Luiz H. Eloy: Advogado formado em direito pela Universidade Católica Dom Bosco - UCDB (2011). Doutorado em Antropologia Social no Museu Nacional - UFRJ, possui Mestrado em Desenvolvimento Local em Contexto de Territorialidades - UCDB (2013). É coordenador da linha de pesquisa Genocídio Indígena no Brasil no Grupo de "Conflitos Armados, Massacres e Genocídios na era Contemporânea" da Universidade Federal de São Paulo - UNIFESP. Fundador do Núcleo de Defesa e Assessoria Jurídica Popular de Mato Grosso do Sul - NAJUP/MS e integrante da Rede Nacional de Advogados e Advogadas Populares - RENAP.

${ }^{7}$ Dados do Departamento Penitenciário Nacional (DEPEN, 2018).
} 
indígenas na justiça brasileira e a necessidade do tratamento diferenciado da legislação especial para populações indígenas envolvidas em processos criminais ou em situação de encarceramento, visando garantir o direito ao exercício de suas particularidades culturais, o que, no senso comum, é entendido como privilégio.

É importante destacar a questão das lutas dos indígenas e a criminalização dos seus movimentos sociais em decorrência do conflito territorial que tem levado os indígenas do Brasil a se tornarem réus, quando na verdade são vítimas das práticas de poder estatal em seu aparelho judiciário que força os indígenas a ocupar espaços cada vez menores.

Visitamos o Tekoha Kunumi Poty Vera, em Caarapó, onde indígenas do povo Guarani-Kaiowa enfrentam processos judiciais decorrentes da luta pelo reconhecimento dos seus territórios tradicionais. Em Juina, noroeste de Mato Grosso, conhecemos Dodowai, indígena do povo Enawene-Nawe impedido de sair de sua aldeia por responder a uma acusação de assassinato. (ELOY, 2018, p.1)

As questões citadas pelo autor refletem a conjuntura da estrutura fundiária do Mato Grosso do Sul, que tem a pior distribuição fundiária do país, sendo zona de conflito entre os ruralistas e indígenas, liderando o ranking dos estados mais violentos contra povos indígenas no Brasil. Segundo Morais (2017, p.77), há um cerco em massa imposto aos Kaiowá e Guarani, que pelo Censo do IBGE contabilizou 11.146 moradores na Reserva de Dourados, não havendo, portanto, espaço para que se firmem lideranças com envergadura suficiente para a mediação dos graves conflitos que se interpõem entre as parentelas; entre os indígenas e os não indígenas, inclusive as dezenas de instituições que atuam nas áreas; e entre os indígenas e os aparelhos de Estado.

Diante deste cenário que envolve questões do poder legal do Estado e a imposição do ordenamento não indígena, que aprisiona os povos originários, tornandoos imputáveis criminalmente, aborda-se adiante a categoria imputabilidade e como ela se relaciona ao ser indígena. Paschoal (2011) afirma que "pertencer a uma cultura diferente não significa ser inimputável. Ter costumes, crenças, hábitos próprios não implica desenvolvimento incompleto, ou retardado" (IBID, p.83). O desenvolvimento mental do índio, independentemente de seu estágio de integração à sociedade "branca", é completo.

\section{$1.1 \mathrm{O}$ indígena réu, o crime e a imputabilidade}

A questão da imputabilidade do indígena, das prisões e seus impactos é um tema que se transformou em folclore muito difundido no imaginário popular brasileiro, uma vez que existem aqueles que pensam serem os índios inimputáveis devido à sua condição de "raça inferior" (incapaz); e outros que admitem ser o indígena capaz quando se trata de lhe cobrar deveres, mas o considera totalmente incapaz quando lhe negam os seus direitos (tirar a carteira de habilitação, documento militar, título de eleitor, entre outros). Assim vejamos:

A Constituição de 1988 reconhece a pluralidade étnica e cultural do país. Assegura a nós os índios o direito à alteridade, é dizer, o direito 
de serem diferentes e tratados como tais, direitos esses, reforçado pela Convenção 169 da OIT, ratificada pelo Brasil em 19.04.2004. O Código Civil em vigor dispõe que a capacidade dos indígenas será regulada por lei especial. Assim, emerge ultrapassada e incorreta qualquer interpretação que trate os índios como inimputáveis ou semiimputáveis em virtude da diferença étnica. (SILVA, 2018, p.2)

Como discorre Silva (2018, p.6), a imputabilidade se mostra presente no próprio ordenamento jurídico que inclui os indígenas como cidadãos brasileiros que, além de deveres, possuem direitos diferenciados e que precisam ser respeitados. Vale ressaltar que o Brasil promulgou, por meio de Decreto presidencial, a Convenção 169 da OIT, que determina que os povos indígenas e tribais deverão ter o direito de conservar seus costumes e instituições próprias, desde que não sejam incompatíveis com os direitos fundamentais definidos pelo sistema jurídico nacional, nem com os direitos humanos internacionalmente reconhecidos. Assim, o indígena acaba sendo enquadrado na justiça não indígena e, como agente capaz, acaba tendo responsabilidades inerentes à sociedade não indígena.

Ao abordar o tema, Wilson Matos da Silva define a imputabilidade como a aptidão do ser humano de compreender que determinado fato não é lícito e de agir em conformidade com esse entendimento. Além disso, o ordenamento penal não tradicional elenca requisitos. Para que a pessoa seja o agente de um crime, dotado de imputabilidade, tem que ter idade de dezoito anos e deverá, à época do fato, estar no gozo de certas faculdades intelectivas e de determinado grau de saúde mental.

Neste interim, esse conceito trazido pelo autor, tendo como referência o jurista Francisco de Assis Toledo, relaciona-se à Teoria Tripartida do $\mathrm{Crime}^{8}$, na qual a constituição do crime se dá pelos seguintes elementos, conforme o quadro a seguir:

\section{QUADRO 01 - CONCEPÇÃO ANALÍTICA FINALISTA DE CRIME (CÓDIGO PENAL BRASILEIRO)}

\begin{tabular}{|c|c|c|}
\hline FATO TÍPICO & $\begin{array}{c}\text { FATO ILÍCITO } \\
\text { (OU ANTIJURÍDICO) }\end{array}$ & FATO CULPÁVEL \\
\hline $\begin{array}{l}\text { a) Conduta (Dolo ou } \\
\text { Culpa; } \\
\text { b) Resultado; } \\
\text { c) Nexo Causal; } \\
\text { d) Tipicidade. }\end{array}$ & $\begin{array}{l}\text { a) Estado de } \\
\text { necessidade; } \\
\text { b) Legítima defesa; } \\
\text { c) Estrito cumprimento } \\
\text { de dever legal; } \\
\text { d) Exercício regular de } \\
\text { direito. }\end{array}$ & $\begin{array}{l}\text { a) Imputabilidade; } \\
\text { b) Potencial consciência } \\
\text { da ilicitude; } \\
\text { c) Exigibilidade de } \\
\text { conduta diversa. }\end{array}$ \\
\hline
\end{tabular}

Fonte: Toledo 2018 (Adaptado)

\footnotetext{
${ }^{8}$ Teoria Tripartida: Cezar Bitencourt, Edgard Magalhães Noronha, Francisco de Assis Toledo, Heleno Fragoso, Aníbal Bruno, Frederico Marques, Nelson Hungria, Juarez Tavares, Guilherme Nucci, Paulo José da Costa Júnior, Luís Régis Prado, Rogério Greco, Fernando Galvão, Hans Wlezel, João Mestieri e David Teixeira de Azevedo.
} 
Nos estudos de Feijó (2015), a qual faz referência a um crime, quando o fato é típico, antijurídico e culpável (nessa ordem). Não existindo qualquer desses elementos, não haverá crime. O terceiro elemento, a culpabilidade, é um juízo de reprovação da conduta do agente que reúne a análise de três circunstâncias:

a) A imputabilidade (se o agente era maior de 18 anos e mentalmente são no momento da conduta);

b) A potencial consciência sobre a ilicitude do fato (não havendo esta consciência o agente pode recair em erro de proibição - art. 21);

c) A exigibilidade de conduta diversa. Não estando presente qualquer dessas circunstâncias o fato não é culpável, afastando, pois, a própria existência do crime.

Sendo assim, para a autora, a imputabilidade é um dos elementos que compõem a culpabilidade, e sem esta não há crime. Entender a responsabilidade penal do indígena significa analisar a sua imputabilidade penal, ou seja, o conjunto de condições pessoais que geram a capacidade do agente para que lhe seja juridicamente atribuível à prática de um fato punível.

\begin{abstract}
A culpabilidade é um juízo de reprovação, que recai sobre o agente por ter atuado de forma contrária ao direito, quando podia agir em conformidade com o mesmo, já a imputabilidade é a aptidão para ser culpável, ou melhor, é a aptidão pessoal para que sua conduta sofra reprovação. Deste modo, é imputável o indivíduo que reúne os dois elementos que a configura, quais sejam: higidez biopsíquica e maturidade legal. Pela maturidade, entende-se o desenvolvimento físico-intelectual que permite ao agente relacionar-se em sociedade de forma independente, equilibrada e emocionalmente segura. $\mathrm{O}$ nosso Diploma Penal consagra a maturidade com base em uma presunção legal, aos 18 anos de idade, sem a possibilidade de perquiri-la caso a caso. (FEIJÓ, 2015 p.72)
\end{abstract}

Seguindo a linha de raciocínio, o autor explica que imputar o sujeito no sistema não tradicional é levar em consideração: a) o critério biológico de uma higidez biopsíquica, relacionada à saúde mental propriamente dita; b) o critério psicológico, que é a capacidade do agente de entender o caráter ilícito de sua conduta, se autodeterminado conforme esse entendimento; ou seja, o agente podia agir de forma diversa, mas não o fez, preferindo, consciente e voluntariamente, delinquir.

Assim, reunidos os dois pressupostos, maturidade e rigidez biopsíquica, o agente é penalmente imputável, apto a sofrer as consequências penais de seus atos. Logo, aquele indígena completamente isolado é considerado inimputável, mas se ele sabe ler, escrever, falar uma língua diferente daquela esperada de um indígena, qualquer uma dessas situações, faz com que ele seja considerado imputável, sem nenhum critério de diferenciação no tratamento jurídico penal.

Souto Maior (2011, p.2), ao refletir sobre o sistema jurídico criminal brasileiro e sua aplicabilidade junto aos indígenas, ressalva a necessidade de averiguar se, de acordo com sua cultura, costume e tradição, ele entendia o caráter ilícito de determinada conduta considerada crime em lei. Assim, não importa determinar o grau de contato que o indivíduo pertencente a um povo indígena mantenha com a sociedade envolvente, mas 
sim, se na ocasião da conduta, ele tinha entendimento de que tal conduta era considerada ilícita.

Neste cenário em que o ordenamento jurídico do "homem branco" vem sendo aplicado aos corpos dos indígenas brasileiros em conflito, temos o poder do Estado no ato de punir que, como será visto a seguir, pode violar os direitos no que tange a diversidade dos sujeitos.

\section{O jus puniendi na alma do indígena imputável}

O Estado, em seu ato de punir os comportamentos tipificados como crime, exerce o jus puniendi, expressão latina que faz referência ao direito de punir do Estado. Refere-se às prerrogativas das práticas de poder sancionadora estatal. Etimologicamente, a expressão jus equivale a direito, enquanto a expressão puniendi equivale a castigar, de forma que se traduzi-la literalmente como o direito de punir ou direito de sancionar, essa expressão é usada sempre em referência ao Estado frente aos cidadãos.

Historicamente, o Estado é sinônimo do poder de punir, tendo o objetivo de assegurar a justa tutela dos bens jurídicos fundamentais, vedando, assim, a justiça privada. Esse jus puniendi estatal pode operar como instância de poder público capaz de resolver o conflito criminal de forma institucional, racional e previsível, formalizada, eficaz e igualitária, com criterioso respeito às garantias individuais.

Para Oliveira (2017, p.2), a natureza do jus puniendi pretende buscar a fundamentação para seus limites com uma principal missão de toda norma, que é estabelecer a obediência onde surge o direito de exigir o seu cumprimento. Antes, quem praticasse um ato contrário à norma estabelecida era punido com castigos físicos. Percebeu-se, no decorrer do tempo, que não é mais ao corpo que se dirige a punição, em suas formas mais duras. Assim para Foucault, não é mais o corpo, é a alma. À expiação que tripudia sobre o corpo deve suceder um castigo que atue, profundamente, sobre o coração, o intelecto, à vontade, às disposições.

Marly formulou o princípio decisivo: Que o castigo, se assim posso exprimir, fira mais a alma do que o corpo. Momento importante. $\mathrm{O}$ corpo e o sangue, velhos partidários do fausto punitivo, são substituídos. Novo personagem entra em cena, mascarado. Terminada uma tragédia, começa a comédia, com sombrias silhuetas, vozes sem rosto, entidades impalpáveis. $\mathrm{O}$ aparato da justiça punitiva tem que ater-se, agora, a esta nova realidade, realidade incorpórea. (FOUCAULT, 2005, p. 18)

Sobre isso é importante fazer referência que, historicamente, a responsabilidade criminal do indígena sempre esteve associada ao grau de civilização ao contato com o homem branco, o quanto ele estava "aculturado". Assim, as relações de poder eram reflexo do modo como o estado brasileiro tratava a sua capacidade civil. Desde a época da Coroa Portuguesa, o indígena foi considerado incapaz para os atos da vida civil enquanto não fosse "civilizado", ou seja, enquanto não fosse incorporado ao modo de vida da sociedade dominante colonial, que buscou, através do processo civilizatório, integrá-lo.

Sem a condição de integrado, o indígena era considerado um ser primitivo, sem desenvolvimento mental completo e, portanto, incapaz de conduzir por si só sua própria 
vida e administrar seus bens. Nesta ótica ele era inimputável, contudo, há de se ressaltar que o estado brasileiro sempre usava seu poder de punir com medidas disciplinadoras, uma vez que, durante o período militar, as prisões para índios já eram uma realidade no Brasil do Serviço de Proteção ao Índio (SPI). Assim, Pequenas cadeias e áreas de confinamento eram mantidas em diversas áreas geridas pelo órgão federal. Segundo Campos (2013):

É o caso, por exemplo, do antigo Posto Indígena Vanuíre, no município de Arco Iris (SP). "Lá também tinha cadeia", explica Ocrides Krenak. Ele próprio conta ter ficado preso no local, na década de 1960. Era uma época em que os servidores do SPI - muitos deles, como Rondon, de origem militar - coibiam com mão de ferro o consumo de álcool nas aldeias. "Eu estava bebendo cachaça, e o chefe de posto percebeu. Mandou-me me apresentar no dia seguinte. Achei que era para fazer algum trabalho, mas não: fiquei preso uns quatro dias.

Assim, o jus puniendi, que dá direito de punir ao Estado, em matéria indígena, existiu muito antes de o indígena ser considerando imputável. O ordenamento jurídico brasileiro tem se organizado para que o aparelho do Estado se faça presente no ato de punir, não somente o corpo, mas a alma indígena, tendo em vista que a prisão não possibilita que os indígenas desenvolvam suas práticas culturais. Privar a liberdade do indígena é aprisionar a sua alma, a sua essência, considerando que, no sistema jurídico tradicional, a pena mais grave é o banimento social ${ }^{10}$, e não a privação da liberdade.

Por isso, para a correta aplicação dos direitos assegurados aos índios nos artigos 56 e 57 do Estatuto do Índio, o operador do direito deve atentar aos conceitos contidos no art. $3^{\circ}$, inciso I, do Estatuto do Índio e no art. 1.2 da Convenção 169 da OIT. Também deve se socorrer do auxílio de profissionais de outras áreas da ciência (antropólogos, sociólogos, psicólogos) e, sobretudo, como afiram Santos Filho (2015, p. 21), sempre que possível deve aferir junto à comunidade indígena se o autor ou acusado pela prática de ilícito é reconhecido por ela como um de seus membros, oportunidade em que poderá aquilatar, inclusive, o reflexo da segregação do réu na sociedade.

O indígena vem sendo julgado pelos tribunais de justiças estaduais do Brasil, o que desmistifica que o indígena seja inimputável, uma vez que ele responde pelos crimes que lhe são imputados no Código Penal brasileiro e, se condenado, pode ter sua liberdade privada em uma instituição total, que pela Lei de Execução Penal, aprisiona sua alma ao lhe impor regras, e o convívio com uma nova maneira de ser, estar e agir fora do seu contexto cultural, de um convívio apartado que desconsidera as legislações especiais elencadas no Estatuto do Índio e a Convecção 169 da OIT.

Cabe aqui ainda fazer referência ao dia 27 de setembro de 2017, no qual houve a aprovação do Projeto de Lei (PLS 513/2013) que trata da reforma da Lei de Execução Penal. Esse projeto aprovado pela Comissão de Constituição, Justiça e Cidadania (CCJ)

\footnotetext{
${ }^{9}$ Medida Disciplinadora: antes do advento do Reformatório Krenak e da Fazenda Guarani, durante a ditadura militar, as prisões para índios já eram uma realidade no Brasil do SPI. Pequenas cadeias e áreas de confinamento eram mantidas em diversas áreas geridas pelo órgão federal. (SPI/BRASIL, 1910).

${ }^{10}$ Banimento Social; essa é a pior pena que pode ser infligida a um índio, na medida que seu afastamento em relação a seu grupo, a sua família, como que lhe limita a identidade e o senso de pertencimento. Em grande medida, os povos indígenas têm uma vivência coletiva muito rica e o banimento é o rompimento desse intenso convívio (Daize Fernanda Wagner, 2018).
} 
do Senado Federal e que seguiu para votação em plenário, em um capítulo especial (cap. III-dos índios), trata exclusivamente dos presos indígenas:

Art. 197-U. A execução da pena dos índios será individualizada e considerará sua organização social, costumes, línguas, crenças e tradições, bem como os métodos aos quais os povos indígenas recorrem tradicionalmente para a sanção penal ou disciplinar de seus membros, utilizando-se, sempre que possível, outros métodos de punição que não o encarceramento. (texto final revisado, termos do art. 65 da Constituição Federal de 1988, pela Câmara dos Deputados referente ao Projeto de Lei do Senado $n^{\circ}$ 513, de 2013, de autoria do Senador Renan Calheiros que trata da Reforma da Lei de Execução Penal, 7 de novembro de 2017)

Assim, a primeira "preocupação" do legislador foi determinar que a execução da pena não poderá impor perda da identidade dos indígenas, que deverão ter respeitados os valores protegidos pela Constituição. $\mathrm{O} \S 5^{\circ}$ do referido artigo trata de falta disciplinar punível com sanção disciplinar, que poderá deixar de ser aplicada se o indígena tiver praticado o fato agindo de acordo com seus costumes, crenças e tradições ou se, em razão desses, tiver dificuldade de compreender ou internalizar as normas disciplinares.

Surge, contudo, a seguinte reflexão: qual profissional poderá ter a possibilidade de avaliar as questões subjetivas da cultura indígena? Os procedimentos disciplinares das unidades prisionais, em grande parte, levam em conta as questões objetivas, $o$ formal da lei, e sem esquecer que quem emite o parecer final é o juiz, que, por vezes, não tem a alteridade para compreender a especificidade de cada etnia.

Diante desse cenário, o Projeto de Extensão da Universidade Federal do ParáUFPA "Meio Ambiente e Povos e Comunidades Tradicionais" e "Indígenas e quilombolas: conhecimento e resistência" realizou um evento, em 05 de maio 2018, com o tema "Prisões e a Criminalização dos Movimentos sociais Indígenas". O Instituto de Ciências Sociais da UFPA, por meio desses projetos de extensão, buscou informar e abrir debates sobre o tema, com a presença de representantes da sociedade civil, professores, acadêmicos indígenas e quilombolas, de diversas áreas do conhecimento.

Tal encontro foi esclarecedor e serviu de base para o presente artigo e para dissertação de mestrado em andamento. Foram debatidas várias situações, como a questão da formação dos alunos do curso de Direito, os impactos das prisões para os indígenas e questões referentes à agência indígena, entre elas a criminalização dos movimentos sociais indígenas e o retrocesso dos direitos em decorrência de uma frente parlamentar em Brasília muito restritiva aos direitos dos povos indígenas - quanto menos direitos melhor para a base ruralista. No que tange à recessão dos direitos dos povos indígenas, Rangel (2015) aponta que:

Os três Poderes - o Executivo, o Legislativo e o Judiciário - são contra os direitos indígenas. Então, há juízes que entendem do problema, o Ministério Público acode, mas a maior parte dos juízes dá ganho de causa para fazendeiros, impedindo o registro de uma terra que foi homologada pelo Presidente da República. No Congresso Nacional, deputados e senadores tentam modificar os direitos constitucionais e o Executivo federal, estadual e municipal também se coloca contra a população indígena. Há casos de prefeituras que 
recebem dinheiro porque têm escola indígena no município, mas não fazem o repasse da verba, o atendimento de saúde é precário e ainda há muita invasão de terras indígenas. (RANGEL, 2015, p.3)

É pertinente ressaltar que essa situação de menos diretos aos indígenas causa choque de interesses entre quem luta para ter acesso aos seus direitos originários e quem não tem compromisso com as agências indígenas e luta contra o acesso a esses direitos, ou seja, as correlações de forças de lutas que não vem sendo diplomáticas e indígenas quem têm lutado pelo que é seu e não possuem esse direito reconhecido efetivamente em todos os poderes, desde quem legisla, executa até quem operacionaliza o direito.

Remetendo à experiência prática e o que foi discutido no evento citado, ficou evidente o desconhecimento de alguns que ali estavam, entre acadêmicos, professores e sociedade civil, da realidade dos indígenas nas prisões e das garantias processuais do réu indígena. É importante ressaltar que os estudantes não são preparados para as questões indígenas, uma vez que se registra uma formação jurídica que padece do entendimento do sistema jurídico tradicional em sua diversidade e da importância da Convenção 169 da OIT, o que é repassado dentro dos blocos de conteúdo da disciplina de Direitos Humanos, com pouca referência à especificidade da cultura indígena no ordenamento jurídico. O que vem sendo difundido são os tratados internacionais em sua evolução nos Direitos Humanos e de quais documentos o Brasil é signatário, mas a questão indígena ainda não é disciplina dentro do cenário acadêmico, o que reflete nas sentenças proferidas envolvendo o réu indígena e as suas garantias processuais.

Essa lacuna ainda está presente na formação dos operadores do direito das universidades brasileiras, sejam elas públicas ou privadas, que apreende a realidade à luz em seu imediato e normativo e, por vezes, preconceituosos, que se refletem nos julgados que envolvem indígenas. Casos antropológicos são tratados como casos de polícia, criminalizados ainda mais pela mídia. E assim as violências vêm ocorrendo, uma vez que "vivemos um problema ético no Brasil, porque o não reconhecimento dos direitos indígenas e dos direitos sociais, em geral, é uma questão que só pode ser discutida e colocada no âmbito da ética" (RANGEL, 2015).

Compreende-se que, para além da formação específica e da ética, a efetivação do direito indígena também depende de quem operacionaliza o direito. Com a reforma da Lei de Execução Penal e o "estanque" em Brasília do Estatuto dos Povos Indígenas, o indígena formalmente e explicitamente passa a fazer parte de um conjunto de normas que o inclui como sujeito imputável de lei não indígena, o qual requer debate mais amplo sobre a disputa sobre direitos diferenciados prevista no Estatuto do Índio e na Convecção 169 da OIT.

Ressalta-se outros relatos, como as experiências vivenciadas pela pesquisadora em São Paulo, em maio de 2018, onde foi realizado um contato pessoal com a advogada e autora Viviane Balbuglio ${ }^{11}$, que, como supracitado, é pesquisadora e desenvolve um trabalho no Assessoramento e Defesa de Direitos do Instituto das Irmãs da Santa Cruz ADDIISC, uma das propostas de atuação direta com povos tradicionais e também com pesquisa relacionada às pessoas indígenas em situação de prisão. O Instituto é também responsável por pesquisas sobre indígenas presos nos estados da federação

\footnotetext{
${ }^{11}$ Viviane Balbuglio é advogada e atua tanto na ADDIISC, como também no ITTC. Na entrevista, ela incialmente fala do trabalho da Dra. Michael, que atua tanto com indígenas quanto com quilombolas em todo o país. No caso dos indígenas, a entidade acompanha a situação da criminalização das lideranças indígenas, principalmente porque envolve luta por terras.
} 
Sobre a situação das garantias processuais do réu indígena, o que se tem presenciado é a invisibilidade étnica do preso indígena e relatos sobre o desconhecimento sobre autodeclaração e desrespeito à Convenção 169 da OIT. Mato Grosso do Sul foi o Estado que forneceu plataforma mais completa, sendo o maior aprisionamento por questão fundiária. Para atender a questão indígena no cárcere, a sua identificação é o primeiro passo para acesso aos direitos, principalmente na defesa de lideranças indígenas. É preciso saber definir o que é indígena, na ótica do indígena.

Em relação ao recenseamento da população encarcerada indígena em São Paulo, a informação é defasada. As autodeclarações acontecem para os defensores públicos, sendo que mais de 200 pessoas se declararam indígenas, número maior do que o registrado nas unidades prisionais. A Súmula 140 do Superior Tribunal de Justiça (STJ) acabou inviabilizando a competência federal.

O que chama a atenção em relação e às falas de Balbuglio (2018) são: 1) a questão da metodologia de identificação do indígena não ser igual para todos os estados da federação; 2) a dificuldade ao acesso à informação e a omissão dessa informação por alguns estados; 3 ) que a autodeclaração pode ocorrer em outro momento e que depende para quem se autodeclarar; 4) sobre o que é ser indígena na história do Brasil; 5) que a condição de pardo inviabiliza a defesa processual apropriada; 6) que se deve levar em conta a condição de ser indígena no cárcere e que é preciso saber os motivos pelo qual o indígena está na condição de pardo? E se por algum motivo que não houve respeito à auto identificação no cárcere em respeito ao modo tradicional de ser? Sem esquecer a polemica do conflito de competência entre a esfera estadual e a esfera federal na apuração de crimes que envolvam indígenas, que desmerecem, por vezes, os laudos antropológicos.

Balbuglio (2018) destaca a importância da atuação do Instituto Terra, Trabalho e Cidadania - ITTC, em São Paulo - instituição que já vem desenvolvendo a pesquisa na base nacional, por entender que tal conhecimento irá contribuir para futuras políticas públicas para a questão indígena e futuros estudos e pesquisas, como a que resultou no presente artigo.

Na justificativa da proposta de Reforma da Lei de Execução Penal, tem-se que o encarceramento é uma punição pouco recorrente entre os povos indígenas, muitas vezes não reconhecidas em seus ordenamentos jurídicos, ela é considerada extremamente severa e desumana, levando-os a optar por outras formas de punição tradicionais para combater as infrações sociais, como o banimento social, o ostracismo, o trabalho comunitário, a reparação do dano à família da vítima, entre outras. $\mathrm{O}$ dispositivo em comento não exclui a possibilidade de encarceramento, mas reduz sua aplicação apenas para os casos realmente necessários.

É pertinente compreender que a temática da justiça criminal e do detento indígena é transdisciplinar e importante no campo das Ciências Jurídicas, Sociais e Antropológicas. Os debates que vêm ocorrendo no país podem fomentar uma política pública para atendimento dos indígenas em situação de cárcere, seja no caso de presos provisórios ou não e de uma sentença diversa do seu sistema jurídico.

Diante deste cenário é importante aqui fazer referência à aprovação pelo Conselho Nacional de Justiça (CNJ) da Resolução específica para tratamento de indígenas acusados, condenados ou privados de liberdade. A norma é resultado de provocação da Fundação Nacional do Índio (FUNAI) ao CNJ, DEPEN e Conselho Nacional de Política Criminal e Penitenciária (CNPCP) em prol da criação de diretrizes que regulamentem tratamento conferido aos indígenas pelo sistema de justiça criminal. 


\section{Resolução 287 do CNJ e os direitos das pessoas indígenas que integram o sistema prisional brasileiro}

Em 25 junho de 2019, o Conselho Nacional de Justiça (CNJ) aprovou a Resolução 287, que assegura os direitos das pessoas indígenas que integram o sistema prisional brasileiro. Essa resolução procura estabelecer procedimentos ao tratamento dado as pessoas indígenas acusadas, rés, condenadas ou privadas de liberdade, como também vem estabelecer diretrizes para assegurar os direitos dessa população no âmbito criminal do Poder Judiciário. Contudo embora o regime jurídico dos indígenas já seja disciplinado por diversos compromissos internacionais firmados pelo Brasil e por regras previstas na legislação brasileira, ainda era preciso suprir essa lacuna existente no que diz respeito à resposta do Poder Judiciário para a questão do indígena privado de liberdade em todo o país.

Essa lacuna se refletia no não respeito aos costumes próprios das comunidades indígenas; não considerando, em grande parte dos casos, no momento da responsabilização penal. Além disso, quando custodiados em unidades prisionais, os indígenas não vinham tendo suas particularidades culturais respeitadas, tais como rituais religiosos e alimentação.

Neste contexto a resolução vem como tentativa de normatizar a questão do "ser índio" que por vezes eram caracterizados pelos operadores do direito por fenótipo - a heteroclassificação do imaginário social do que ser índio no Brasil na ótica do assimilacionismo. Assim todas as pessoas que se autodeclarem como indígenas, brasileiros ou não, falantes tanto da língua portuguesa quanto de línguas nativas, independentemente do local de moradia, em contexto urbano, acampamentos, assentamentos, áreas de retomada, terras indígenas regularizadas e em diferentes etapas de regularização fundiária, deve-se neste caso proceder respeitando autodeterminação em qualquer fase do processo criminal ou na audiência de custódia.

A resolução acentua ainda que em caso de autodeclaração do indígena, a autoridade judicial deverá identificar a etnia, a língua falada e do grau de conhecimento da língua portuguesa e as cópias dos autos do processo deverão ser encaminhadas à regional da FUNAI mais próxima em até 48 (quarenta e oito) horas.

Vale ressaltar ainda, que um manual será elaborado pelo CNJ para orientar a implementação das medidas previstas na Resolução, que entra em vigor noventa dias após sua publicação. A norma estabelece procedimentos ao tratamento das pessoas indígenas acusadas, rés, condenadas ou privadas de liberdade, e dá diretrizes para assegurar os direitos dessa população no âmbito criminal, observando os ditames da Declaração da Organização das Nações Unidas (ONU) sobre os direitos dos povos indígenas e da Convenção no 169 da OIT.

Alguns dos procedimentos previstos na Resolução:

a) A autoridade judicial buscará garantir a presença de intérprete, preferencialmente membro da própria comunidade indígena, em todas as etapas do processo em que a pessoa indígena figure como parte: I - 
se a língua falada não for a portuguesa; II - se houver dúvida sobre o domínio e entendimento do vernáculo, inclusive em relação ao significado dos atos processuais e às manifestações da pessoa indígena - III. mediante solicitação da defesa ou da Funai; IV - a pedido de pessoa interessada; b) Possibilidade de realização de perícia antropológica, que fornecerá subsídios para o estabelecimento da responsabilidade da pessoa acusada; c) A responsabilização de pessoas indígenas deverá considerar os mecanismos próprios da comunidade indígena a que pertença a pessoa acusada, mediante consulta prévia; d) Qualquer medida cautelar alternativa à prisão deverá se adaptar às condições e aos prazos que sejam compatíveis com os costumes, o local de residência e as tradições da pessoa indígena; e) Definição de pena e regime de cumprimento considerando características culturais, sociais e econômicas, suas declarações e a perícia antropológica, de modo a: I- aplicar penas restritivas de direitos adaptadas às condições às condições e prazos compatíveis com os costumes, local de residência e tradições da pessoa indígena; II - considerar a conversão da multa pecuniária em prestação de serviços à comunidade, nos termos previstos em lei; III determinar o cumprimento da prestação de serviços à comunidade, sempre que possível e mediante consulta prévia, em comunidade indígena.

Sobre a necessidade desta resolução ela se deu em decorrência dos casos de prisão trazidos pelas coordenações regionais da FUNAI que começou em novembro de 2018 a buscar parcerias com órgãos da justiça criminal para tentar estabelecer normativo que tratasse a questão, tendo em vista que, até então, não existia no ordenamento jurídico brasileiro uma norma específica para o tratamento do indígena pelo sistema de justiça criminal. Neste interim a normativa que representa avanço na garantia dos direitos humanos da população indígena, requer o empenho de todos os setores estatais e da própria sociedade civil organizada para que esta realmente se efetive na vida do indígena em conflito com a lei.

\section{Considerações finais}

O presente artigo buscou trazer uma reflexão o poder do estado e a prática jurídica no Brasil nos casos dos processos criminais que envolvem indígena. Diante da complexidade do problema, sobre o qual não se tem muitas referências específicas, os dois autores indígenas encontrados foram de grande valia para a elaboração do texto, pois ninguém pode falar melhor da realidade indígena do que eles mesmos, principalmente quando se busca compreender o sistema jurídico tradicional e não tradicional. Daí se ter feito referência aos indígenas advogados do Mato Grosso do Sul, onde há os maiores índices de presos indígenas, tema este ainda pouco discutido na Região Amazônica, mesmo sendo está também zona de conflito de populações que lutam pela sua sobrevivência e biodiversidade.

A revisão de bibliografia possibilitou ampliar o olhar sobre o jus puniendi na alma do indígena imputável nas práticas do poder do Estado e o contexto histórico nas quais são inseridas. Debate este que requer além dos textos clássicos do direito penal, 
processo penal e execução penal escritas pelo "homem branco", autores indígenas que, no seu cotidiano e militância política, ajudam a construir saberes.

É preciso enfrentar ainda a questão do reconhecimento pelo estado brasileiro das normas consuetudinárias dos diversos grupos tribais. Sem descuidar da questão da soberania nacional e da separação dos poderes, demonstrando que aceitar a aplicação do direito costumeiro das comunidades significa dar efetividade à vontade constitucional, que estruturou um sólido sistema de proteção à diversidade cultural brasileira, tendo assegurado inúmeros direitos aos povos indígenas no afã de promover essa reprodução física e cultural de minorias étnicas.

Neste sentido, a temática sobre a prisão do indígena e a realidade no sistema carcerário do brasileiro ganhou mais escopo e materialidade ao ter elementos para interpretar a questão, uma vez que a prisão para o indígena é o aprisionamento da alma, o cerceamento das suas práticas culturais. Grandes lideranças indígenas explanam sobre a realidade dos indígenas em prisão. Ela representa o etnocídio do indígena, pois o seu aprisionamento impossibilita a prática cultural, e com diz o indígena advogado Wilson matos da Silva: "um homem sem cultura seria um homem sem chão".

\section{Referências}

BRASIL, SUPERIOR TRIBUNAL DE JUSTIÇA. Súmula no 140. Compete à Justiça Comum Estadual processar e julgar crime em que o indígena figure como autor ou vítima. Disponível em; <https://ww2.stj.jus.br/docs_internet/revista/eletronica/stjrevista-sumulas_Sumula140.pdf $>$. Acesso em 30 ago.2018.

BRASIL. Decreto-Lei 2.848, de 07 de dezembro de 1940. Código Penal. Diário Oficial da União, Rio de Janeiro, 31 dez. 1940. Disponível em: $<$ www2.camara.leg.br/.../declei/1940.../decreto-lei-2848-7-dezembro>. Acesso em 30 ago.2018.

BRASIL. Fundação Nacional do Índio - FUNAI. Órgão indigenista oficial do Estado brasileiro. Criada por meio da Lei ${ }^{0} 5.371$, de 5 de dezembro de 1967. Disponível em: $<$ http://www.funai.gov.br>. Acesso em 10 set.2018.

BRASIL. Ministério da Justiça. Estatuto Dos Povos Indígenas, Lei nº 6.001/1973. Disponível em: <http://www.funai.gov.br/arquivos/conteudo/presidencia/pdf/Estatutodo-Indio_CNPI/pdf>. Acesso em 05 set. 2018.

BRASIL. Constituição Federal de 1988. Art. 65 aprovado pela Câmara dos Deputados referente ao Projeto de Lei do Senado $\mathbf{n}^{\mathbf{0}}$ 513, de 2013, que trata da Reforma da Lei de Execução Penal, 7 de novembro de 2017. Disponível em: <www.planalto.gov.br/ccivil_03/constituição/htm>. Acesso em 05 set.2018.

BRASIL. Conselho Nacional de Justiça, 2019. Resolução 287, de 25 de junho de 2019. Disponível em: <http://www.cnj.jus.br/atos-normativos?documento=2959>. Acesso em 17 ago.2019. 
CAMPOS, A. Prisões e castigos para “civilizar os índios”. 2013. Disponível em: $<$ https://apublica.org/2013/06/prisoes-castigos-para-civilizar-os-indios/>. Acesso em: 09 jul.2018.

CASTILHO, E. W. V. Indígena na Prisão: o Déficit da Perspectiva Intercultural.IN: Lei do Índio ou Lei do Branco-Quem decide? Sistemas jurídicos Indígenas e Intervenções Estatais. CASTILHO, E. W. V; OLIVEIRA, A. C. (Coord.). Rio de Janeiro: Editora Lumen Juris. 2019 (PP. 127-156)

ELOY, L. H. Os índios não respondem pelos seus atos: Mato Grosso do Sul tem a maior população carcerária indígena do país. 2018. Disponível em: $<$ http://tvbrasil.ebc.com.br/indio-presente/2018/04/os-indios-nao-respondem-pelosseus-atos>. Acesso em 08 jul.2018.

FEIJÓ, J. H. C. S. F. O Direito Penal E O Índio: Desafios Históricos Sob a Nova Perspectiva Constitucional. Revista Eletrônica do Mestrado em Direito da UFAL. V. 6, N. 1 (2015). Constitucionalização dos direitos humanos fundamentais. 2015. ISSN 1809-1873. Disponível em: $<$ www.seer.ufal.br/index.php/rmdufal/article/viewFile/1827/1335>. Acesso em 13 set.2017.

FOUCAUlT, M. Microfísica do poder. São Paulo. Petrópolis: Vozes, 2015. (Introdução, capítulo 1).

FOUCAUlT, M. Vigiar e Punir: nascimento da prisão. 30. São Paulo, Petrópolis: Vozes, 2005.

FOUCAULT, M. Segurança, Território, População. Curso dado no College de France (1977- 1978). São Paulo: Martins Fontes, 2008.

MORAIS, B. M. Crônicas da territorialidade Kaiowá e Guarani nas adjacências da morte. São Paulo: Elefante, 2017.

NUCCI, G. S. Código penal comentado. São Paulo: Editora Revista dos Tribunais, 2006.

OLIVEIRA, D. Jus Puniendi Do Estado E Sua Reparação. IN: JUSBRASIL. Disponível em: $\quad<$ https://dannyeleoliveira.jusbrasil.com.br/artigos/448814173/juspuniendi-do-estado-e-sua-rep.>. Acesso em 08 jul.2018.

ORGANIZAÇÃO INTERNACIONAL DO TRABALHO. Convenção $\mathbf{n}^{\mathbf{0}} \mathbf{1 6 9}$ sobre povos indígenas e tribais e Resolução referente à ação da OIT. Brasília: OIT, 2011. Disponível em: $<$ www.planalto.gov.br/ccivil_03/_ato20042006/2004/decreto/d5051>. Acesso em 09 set.2018.

PASCHOAL, J. C. O Índio, a Imputabilidade e o Preconceito. IN: Direito e Povos Indígenas, VILLARES, L. F. (coord.). / 1ª reimp. / Curitiba: Juruá, 2011. P. 81-93. 
RANGEL, L. H. Violência contra os indígenas é um problema ético. IN: Violência contra os indígenas é um problema ético. CIMI, 2015. Disponível em: $<$ https://cimi.org.br/pub/relatorio/Relatorio-violencia-contra-povos-indigenas_2015Cimi.pdf $>$. Acesso em 10 set.2018.

SANTOS FILHO, R. L. Índios: Prisão Cautelar e Cumprimento de Pena Privativa de Liberdade às luzes do Estatuto do Índio e da Convenção 169 da OIT. Revista do Tribunal Regional Federal da $3^{\text {a }}$ Região ${ }^{\circ}$ 84, julho-agosto. 2007. Disponível em: $<$ http://www.ibrajus.org.br/revista/artigo.asp?idArtigo=63>. Acesso em 20 nov.2017.

SILVA, W. M. Da imputabilidade penal do índio. Revista Direito GV, São Paulo. VOL. $14 \quad \mathrm{n}^{\circ}$. 1, Jan - Abr, 2018. Disponível em: $<$ https://www.douradosagora.com.br/noticias/entretenimento/da-imputabilidade-penaldo-indio-wilson-matos-da-silva>. Acesso em 05 jan.2018.

SILVA, W. M. (IN) Imputabilidade Penal do Índio: verdade ou mentira. 2018. Disponível em: <http://www.progresso.com.br/opiniao/wilson-matos/in-imputabilidadepenal-do-indio-verdade-ou-mentira. Acesso em 05 jan.2018.

SOUTO MAIOR, A. P. C. Imputabilidade Penal. Disponível em: $<$ http://www.isa.gov.br>. Junho de 2011. Acesso em: 10 set.2018.

WAGNER, D, F. A Pena Privativa de Liberdade entre os Povos Indígenas do Oiapoque: modelo próprio de execução penal? IN: Publica Direito. 2018. Disponível em: $<$ www.publicadireito.com.br/artigos/?cod=0cf5d42e34cfeb8a $>$. Acesso em 07 jul.2018. 